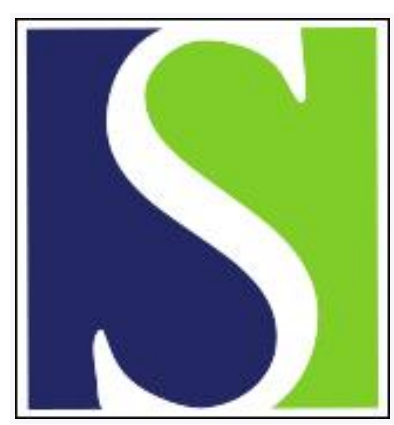

Scand J Work Environ Health 1998;24(4):270-275

https://doi.org/10.5271/sjweh.320

Issue date: Aug 1998

Mortality and cancer incidence among Swedish paint industry workers with long-term exposure to organic solvents

by Lundberg I, Milatou-Smith R

The following article refers to this text: $2015 ; 41(6): 579-593$

Key terms: cohort study; multiple myeloma; prostate cancer; update; xylene

This article in PubMed: www.ncbi.nlm.nih.gov/pubmed/9754858

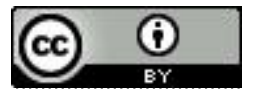




\title{
Mortality and cancer incidence among Swedish paint industry workers with long-term exposure to organic solvents
}

\author{
by Ingvar Lundberg, MD, ${ }^{+}$Rodothea Milatou-Smith, MD
}

\begin{abstract}
Lundberg I, Milatou-Smith R. Mortality and cancer incidence among Swedish paint industry workers with longterm exposure to organic solvents. Scand J Work Environ Health 1998;24(4):270-275.

Objectives The aim of this update on a cohort of male paint industry workers was to determine whether an excess of mortality and incidence of lymphatic and hematopoietic tumors, particularly multiple myeloma, still exists, and, if so, to determine if it is due to exposures occurring before the mid-1950s, when benzene disappeared as a solvent in the Swedish paint industry.

Methods The cohort of 411 men who had worked in the Swedish paint industry and had been exposed to organic solvents for at least 5 years during $1955-1975$ was followed from 1961 to 1994 for causes of death in the mortality register and from 1961 to 1992 for cases of cancer in the Swedish cancer register.

Results The number of paint industry workers who had died, plus the number of deaths in the major disease groups and the number of cancers reported to the cancer registry, was close to the expected. The incidence of prostatic cancer increased somewhat [standardized incidence ratio (SIR) $1.5,95 \%$ confidence interval (95\% CI) $1.0-2.2$ ]. Among the workers first employed in 1956 or earlier, there was an increase in both the incidence and mortality from all lymphatic and hematopoietic tumors [SIR 2.3, 95\% CI 1.0-2.2; standardized mortality ratio (SMR) 2.0, $95 \%$ CI 0.7 -4.4]. The excess was particularly marked for multiple myeloma (SIR 3.8, 95\% CI $0.8-11$; SMR 4.4, 95\% CI $0.9-13$ ).

Conclusions Employment in the Swedish paint industry before 1957 may have entailed some excess risk of lymphatic and hematopoietic tumors, particularly multiple myeloma. A significant excess of prostatic cancer was not linked to any particular employment period and deserves further investigation.
\end{abstract}

Key terms cohort study, multiple myeloma, prostatic cancer, update, xylene.

Paint manufacturing workers have been heavily exposed to different organic solvents, for example, white spirit, xylene and toluene, for many decades. In Sweden benzene was a widely used solvent until the mid-1950s when its use was prohibited due to the health hazards involved. The exposure to agents other than solvents, such as binders, pigments, and adhesives, has been limited to the job of charging raw materials (1).

The painting has been considered carcinogenic as an occupation by the International Agency for Research on Cancer (IARC) mainly due to consistent excesses of lung and urinary bladder cancer found in several studies, while the evidence for the carcinogenicity of occupational exposure in paint manufacturing is considered inadequate due to the inconsistent results of the few studies performed (2).

Three cohort studies of the cancer risk, or possible excess mortality from other diagnoses, in the paint manufacturing industry have been published. In the United States, Morgan et al $(3,4)$ showed higher than expected rates from cancer of the colon and rectum; these rates were unlikely to be caused by work environment exposures. The researchers also showed increased rates, although the numbers were smaller, for liver and biliary cancers among the workers handling pigments and for leukemia among the workers in lacquer production. The exposure of the lacquer workers had probably included benzene $(3,4)$. In Italy 427 workers in the paint manufacturing industry were followed (5). They showed a significant excess of lung cancer based on small numbers. These workers were exposed to both asbestos and chromate pigments. In Sweden we have followed a small cohort of men who had been employed for more than 5 years in the Swedish paint manufacturing industry. In the first follow-up increased mortality from multiple myeloma was found on the basis of 3 cases (1).

1 Department of Occupational Health, Karolinska Hospital, Stockholm, Sweden.

2 Department of Occupational Health, National Institute for Working Life, Solna, Sweden.

Reprint requests to: Dr Ingvar Lundberg, Department of Occupational Health, Karolinska Hopital, S-171 76 Stockholm Sweden. [e-mail: ingvarl@ymed.ks.se] 
During the 1980 s and 1990 s several authors found increased mortality from non-Hodgkin's lymphoma for workers exposed to the chlorinated solvents trichloroethylene and tetrachloroethylene (6). Increased risk has also been found among workers exposed to nonchlorinated solvents in several case-referent studies (7-13).

The aim of this new follow-up of the Swedish cohort is to contribute to a better understanding of the possible carcinogenicity of exposures in paint manufacturing. Specifically we wanted to investigate whether there was an excess of hematopoietic tumors, particularly myelomas and non-Hodgkin lymphomas. If such an excess could be found, we wanted to determine whether it could be attributed to exposures occurring before the mid-1950s, when benzene disappeared as a solvent in the industry.

\section{Subjects and methods}

\section{Exposure}

The exposure conditions in the Swedish paint industry until the mid-1980s were described in our previous publication (1). Information regarding exposures before 1950 was very limited. Xylene and, less often, toluene were the most common constituents of the air exposure between the early 1950 s and the mid-1980s. Improvements leading to reduced total solvent exposures started in the mid-1960s. No profound changes in exposure seem to have occurred in Swedish paint factories since the mid1980s.

The exposure in different factories and different tasks was considered similar, except for cleaners. This group was considered to be very heavily exposed. The cleaners manually cleaned paint-mixing equipment with solvents (1).

\section{Subjects}

The cohort consisted of all male employees who had worked for more than 5 years in a solvent-exposed environment during the period 1955 to 1975 in 9 paint manufacturing companies in southern Sweden.

Many of the workers had performed a number of tasks during their employment, and their individual work histories could not be obtained. However, a small group of 30 workers who had worked as cleaners for at least 2 years was identified within the cohort.

The cohort studied in 1986 consisted of 416 men (1). Since then 5 men, as judged from their names as previous immigrants, had emigrated, while the remaining 411 could be identified as dead or alive in 1995. The immigrants were excluded from the cohort since illness may be a common reason for returning to the country of origin. In fact we have received information that 2 of the 5 emigrants had died within 2 years of returning to their home country.

Thus the study followed 411 men. Thirty of them had been cleaners for at least 2 years. They were followed from 1961 to 1994 for causes of death and from 1961 to 1992 for cases of cancer in the Swedish cancer register. Between 1961 and 1994, 9761 person-years were observed. In the previous publication the cohort was followed until 1981 for deaths and to 1980 for cancer incidence.

Two exposure groups were formed according to the median of the start of employment, 1956. This time also coincided well with the time when benzene had disappeared as a single solvent in the industry (1). Altogether 215 men were employed in 1956 or earlier, while 196 were employed in 1957 or later.

\section{Methods}

The expected numbers of death and cancers were calculated by multiplying the person-years of observation within 5-year age categories during the respective calendar years of the study period by the cause-, gender-, and age-specific national death and cancer incidence rates. The computer package OCMAP (14) was used for the calculations. The $95 \%$ confidence intervals of the observed to expected ratios were calculated based on the Poisson distribution.

Analyses were performed for the entire material, as well as for the cleaners separately. Separate analyses were also made for the men who were employed in 1956 or earlier and in 1957 or later and with requirements for at least 5,15 , or 30 years between first employment and death or cancer diagnosis. Analyses were also made separately for the 1961-1981 and 1982-1994 (deaths) and 1961-1980 and 1981-1992 (cancer incidence) time periods.

Copies of the death certificates were obtained from the National Bureau of Statistics.

\section{Results}

\section{Causes of death}

Among the paint industry workers, 207 had died between 1961 and 1994, compared with 218 expected deaths. There were 111 new deaths since 1981, compared with 114 expected. The number of deaths from malignant tumors, and from other major diseases, was also close to the expected number (table 1).

There was an increase in the number of deaths from hematopoietic tumors, 7 observed between 1961 and 
Table 1. Observed $(0)$ and expected $(E)$ number of deaths among Swedish paint industry workers with at least 5 years of employment between 1955 and 1975 and no further requirement concerning time between first exposure and observation. (SMR = standardized mortality ratio, $95 \% \mathrm{Cl}=95 \%$ confidence interval)

\begin{tabular}{|c|c|c|c|c|c|c|c|c|c|c|c|c|}
\hline \multirow[t]{2}{*}{ Cause of death ${ }^{a}$} & \multicolumn{4}{|c|}{$1961-1994$} & \multicolumn{4}{|c|}{$1961-1981$} & \multicolumn{4}{|c|}{$1982-1994$} \\
\hline & 0 & $E$ & SMR & $95 \% \mathrm{Cl}$ & 0 & E & SMR & $95 \% \mathrm{Cl}$ & 0 & $E$ & SMR & $95 \% \mathrm{Cl}$ \\
\hline All causes $(1-999)$ & 207 & 218 & 1.0 & $0.8-1.1$ & 96 & 104 & 0.9 & $0.8-1.1$ & 111 & 114 & 1.0 & $0.8-1.2$ \\
\hline Tumors, all sites (140-209) & 50 & 50 & 1.0 & $0.7-1.3$ & 22 & 25 & 0.9 & $0.6-1.3$ & 28 & 25 & 1.1 & $0.7-1.6$ \\
\hline $\begin{array}{l}\text { Lung (162) } \\
\text { Prostate (185) } \\
\text { Lymphatic and hematopoietic tissues (200-209) } \\
\text { Malignant lymphoma (200-202) } \\
\text { Multiple myeloma (203) } \\
\text { Leukemia (204-207) }\end{array}$ & $\begin{array}{l}10 \\
11 \\
7 \\
1 \\
4 \\
2\end{array}$ & $\begin{array}{l}9.0 \\
7.9 \\
4.6 \\
1.7 \\
1.1 \\
1.7\end{array}$ & $\begin{array}{l}1.1 \\
1.4 \\
1.5 \\
0.6 \\
3.8 \\
1.2\end{array}$ & $\begin{array}{l}0.5-2.0 \\
0.7-2.5 \\
0.6-3.1 \\
0.0-3.3 \\
1.0-9.7 \\
0.2-4.3\end{array}$ & $\begin{array}{l}3 \\
3 \\
5 \\
1 \\
3 \\
1\end{array}$ & $\begin{array}{l}4.5 \\
3.0 \\
2.4 \\
0.8 \\
0.5 \\
0.9\end{array}$ & $\begin{array}{l}0.7 \\
1.0 \\
2.1 \\
1.2 \\
5.7 \\
1.1\end{array}$ & $\begin{array}{l}0.1-1.9 \\
0.2-2.9 \\
0.7-4.9 \\
0.0-6.6 \\
1.2-17 \\
0.0-6.3\end{array}$ & $\begin{array}{l}7 \\
8 \\
2 \\
\frac{1}{1} \\
1\end{array}$ & $\begin{array}{l}4.5 \\
4.9 \\
2.2 \\
0.8 \\
0.5 \\
0.8\end{array}$ & $\begin{array}{r}1.6 \\
1.6 \\
0.9 \\
0 \\
1.9 \\
1.3\end{array}$ & $\begin{array}{l}0.6-3.2 \\
0.7-3.2 \\
0.1-3.3 \\
0.0-4.4 \\
0.1-10 \\
0.0-7.1\end{array}$ \\
\hline Diseases of the circulatory system (390-458) & 110 & 117 & 0.9 & $0.8-1.1$ & 46 & 53 & 0.9 & $0.6-1.2$ & 64 & 63 & 1.0 & $0.8-1.3$ \\
\hline Ischemic heart disease $(410-414)$ & 77 & 79 & 1.0 & $0.8-1.2$ & 34 & 38 & 0.9 & $0.6-1.2$ & 43 & 40 & 1.1 & $0.8-1.4$ \\
\hline Diseases of the respiratory system $(460-519)$ & 14 & 13 & 1.0 & $0.6-1.7$ & 8 & 4.8 & 1.7 & $0.7-3.3$ & 6 & 9.1 & 0.7 & $0.2-1.4$ \\
\hline $\begin{array}{l}\text { Chronic obstructive lung disease (490-493) } \\
\text { Cirrhosis of the liver }(571)\end{array}$ & $\begin{array}{l}6 \\
5\end{array}$ & $\begin{array}{l}4.6 \\
2.5\end{array}$ & $\begin{array}{l}1.3 \\
2.0\end{array}$ & $\begin{array}{l}0.5-2.8 \\
0.7-4.7\end{array}$ & $\begin{array}{l}3 \\
4\end{array}$ & $\begin{array}{l}2.0 \\
1.6\end{array}$ & $\begin{array}{l}1.5 \\
2.4\end{array}$ & $\begin{array}{l}0.3-4.3 \\
0.7-6.2\end{array}$ & $\begin{array}{l}3 \\
1\end{array}$ & $\begin{array}{l}2.6 \\
0.9\end{array}$ & $\begin{array}{l}1.2 \\
1.2\end{array}$ & $\begin{array}{l}0.2-3.4 \\
0.0-6.6\end{array}$ \\
\hline Diseases of the genitourinary system $(580-607)$ & 5 & 3.5 & 1.4 & $0.5-3.3$ & 5 & 1.7 & 2.9 & $0.9-6.7$ & - & 1.8 & 0 & $0.0-2.1$ \\
\hline Accidental deaths $(800-999)$ & 14 & 12 & 1.1 & $0.6-1.9$ & 9 & 7.9 & 1.1 & $0.5-2.2$ & 5 & 4.4 & 1.14 & $0.4-2.7$ \\
\hline
\end{tabular}

a Code of the International Classification of Diseases, 8th revision, in parentheses.

Table 2. Mortality (1961-1994) and cancer incidence (1961-1992) for selected diagnoses among workers employed up to and including 1956 or 1957 or later. $(0=$ observed number of deaths or cases, SMR = standardized mortality ratio, SIR = standardized incidence ratio, $95 \% \mathrm{Cl}=95 \%$ confidence interval)

\begin{tabular}{|c|c|c|c|c|c|c|c|c|c|c|c|c|}
\hline \multirow[t]{3}{*}{ Diagnosis } & \multicolumn{6}{|c|}{ First employment 1956 or earlier } & \multicolumn{6}{|c|}{ First employment 1957 or later } \\
\hline & \multicolumn{3}{|c|}{ Mortality } & \multicolumn{3}{|c|}{ Gancer incidence } & \multicolumn{3}{|c|}{ Mortality } & \multicolumn{3}{|c|}{ Cancer incidence } \\
\hline & 0 & SMR & $95 \% \mathrm{Cl}$ & 0 & SIR & $95 \% \mathrm{Cl}$ & 0 & SMR & $95 \% \mathrm{Cl}$ & 0 & SIR & $95 \% \mathrm{Cl}$ \\
\hline All causes & 129 & 0.9 & $0.8-1.1$ & - & $\cdot$ & . & 78 & 1.0 & $0.8-1.3$ & - & & . \\
\hline All malignant tumors & 38 & 1.2 & $0.8-1.6$ & 55 & 1.1 & $0.8-1.4$ & 12 & 0.7 & $0.4-1.2$ & 28 & 1.0 & $0.6-1.4$ \\
\hline $\begin{array}{l}\text { Prostate } \\
\text { All lymphatic and hematopoietic } \\
\text { Mulitiple myeloma }\end{array}$ & $\begin{array}{l}9 \\
6 \\
3\end{array}$ & $\begin{array}{l}1.7 \\
2.0 \\
4.4\end{array}$ & $\begin{array}{l}0.8-3.2 \\
0.7-4.4 \\
0.9-13\end{array}$ & $\begin{array}{c}18 \\
9 \\
3\end{array}$ & $\begin{array}{l}1.5 \\
2.3 \\
3.8\end{array}$ & $\begin{array}{l}0.9-2.4 \\
1.0-4.3 \\
0.8-11\end{array}$ & $\begin{array}{l}2 \\
1 \\
1\end{array}$ & $\begin{array}{l}0.8 \\
0.6 \\
2.7\end{array}$ & $\begin{array}{l}0.1-2.7 \\
0.0-3.4 \\
0.1-15\end{array}$ & $\begin{array}{l}9 \\
1 \\
1\end{array}$ & $\begin{array}{l}1.4 \\
0.4 \\
2.2\end{array}$ & $\begin{array}{l}0.6-2.7 \\
0.0-2.4 \\
0.1-12\end{array}$ \\
\hline
\end{tabular}

1994 versus 4.6 expected. Two new deaths occurred after 1981 compared with 2.2 expected. The mortality did not increase or decrease with increasing time since first employment. Six of the 7 deaths had occurred among workers employed before 1957 (table 2).

There was especially an increase noted in the number of deaths from multiple myeloma [4 observed deaths, 1.1 expected, standardized mortality ratio (SMR) $3.8,95 \%$ confidence interval $(95 \% \mathrm{CI}) 1.0-9.7]$. One of these deaths, versus 0.5 expected, had occurred since 1982. All 4 deaths remained when the cohorts were analyzed with a requirement for at least 15 years since the start of employment (0.9 expected, SMR 4.3, 95\% CI 1.2-10).

There was only 1 death from non-Hodgkin lymphoma compared with 1.7 expected.

Eleven deaths from prostatic cancer were observed between 1961 and 1994, compared with 7.9 expected. Eight of the prostatic cancer deaths were new since 1981, compared with 4.9 expected. There was no difference in prostatic cancer mortality between the groups with different requirements for time since first employment or between those employed before 1957 or 1957 and later (table 2).

In the previous follow-up until 1981, 3 deaths from genitourinary diseases, all infections, were found among the cleaners. This result implied a markedly increased risk, but in the new follow-up period there were no deaths in the cohort from such causes.

\section{Cancer incidence}

The incidence for all cancer diagnoses between 1961 and 1992 was close to the expected ( 83 observed, 80 expected) (table 3).

The incidence of lymphatic and hematopoietic tumors was increased (10 observed, 6.3 expected). Nine of the 10 cases had occurred among those employed before 1957 [standardized incidence ratio (SIR) 2.3, 95\% CI 1.0-4.3] (table 2). The SIR values did not differ between the groups with different times since first employment. 
Table 3. Cancer incidence, 1961-1992, for the Swedish paint industry workers with at least 5 years of employment between 1955 and 1975 and no further requirement concerning time between first exposure and observation. $(0=$ observed number of cases, $E=$ expected number of cases, SMR = standardized mortality ratio, $95 \% \mathrm{Cl}=95 \%$ confidence interval)

\begin{tabular}{|c|c|c|c|c|c|c|c|c|c|c|c|c|}
\hline \multirow[t]{2}{*}{ Cancer site ${ }^{\mathrm{a}}$} & \multicolumn{4}{|c|}{$1961-1992$} & \multicolumn{4}{|c|}{$1961-1980$} & \multicolumn{4}{|c|}{$1981-1992$} \\
\hline & 0 & $E$ & SIR & $95 \% \mathrm{Cl}$ & 0 & $E$ & SIR & $95 \% \mathrm{Cl}$ & 0 & $E$ & SIR & $95 \% \mathrm{Cl}$ \\
\hline All malignant tumors (140-209) & 83 & 80 & 1.0 & $0.8-1.3$ & 36 & 37 & 1.0 & $0.7-1.3$ & 47 & 43 & 1.1 & $0.8-1.5$ \\
\hline Colon (153) & 9 & 5.8 & 1.6 & $0.7-2.9$ & 2 & 2.7 & 0.7 & $0.1-2.7$ & 7 & 3.1 & 2.2 & $09-4.6$ \\
\hline Rectum and anus (154) & 3 & 4.0 & 0.7 & $0.2-2.1$ & $\overline{1}$ & 1.9 & 0.5 & $0.0-2.9$ & 2 & 2.0 & 1.0 & $0.1-3.4$ \\
\hline Biliary passages and liver (155) & 2 & 2.1 & 0.9 & $0.1-3.4$ & 1 & 1.0 & 1.0 & $0.0-5.7$ & $\overline{1}$ & 1.2 & 0.9 & $0.2-4.8$ \\
\hline Bronchus and lung (162.1) & 6 & 8.5 & 0.7 & $0.3-1.5$ & 1 & 4.3 & 0.2 & $0.0-1.3$ & 5 & 4.2 & 1.2 & $0.4-2.8$ \\
\hline Prostate (177) & 27 & 18 & 1.5 & $1.0-2.2$ & 9 & 7.1 & 1.3 & $0.6-2.4$ & 18 & 11 & 1.6 & $10-2.6$ \\
\hline Lymphatic and hematopoietic $(200-209)$ & 10 & 6.3 & 1.6 & $0.8-2.9$ & 5 & 3.1 & 1.6 & $0.5-3.8$ & 5 & 3.3 & 1.5 & $0.5-3.6$ \\
\hline Non-Hodgkin lymphoma $(200)$ & 2 & 2.1 & 1.0 & $0.1-3.4$ & 1 & 0.9 & 1.1 & $0.0-6.3$ & 1 & 1.2 & 0.8 & $0.0-4.6$ \\
\hline Multiple myeloma (203) & 4 & 1.2 & 3.2 & $0.9-8.3$ & 3 & 0.6 & 5.1 & $1.1-15$ & 1 & 0.7 & 1.5 & $0.0-8.6$ \\
\hline Leukemia (204-207) & 3 & 2.1 & 1.5 & $0.3-4.3$ & 1 & 1.1 & 0.9 & $0.0-5.3$ & 2 & 1.0 & 2.0 & $0.2-7.2$ \\
\hline Chronic lymphatic leukemia (204.1) & 2 & 0.9 & 2.1 & $0.3-7.7$ & - & 0.5 & 0 & $0.0-8.0$ & 2 & 0.5 & 4.2 & $0.5-15$ \\
\hline
\end{tabular}

a Code of the International Classification of Diseases, 7 th revision, in parentheses.

The incidence was increased for multiple myeloma (4 observed, 1.2 expected, SIR 3.2, 95\% CI $0.9-8.3$ ). All 4 cases remained when the cohort was analyzed with a requirement for at least 15 years since first employment (1.1 expected, SIR 3.7, 95\% CI 1.0-9.5).

There were 2 incident cases of non-Hodgkin's lymphoma versus 2.1 expected.

Some increase occurred in the incidence of prostatic cancer ( 27 observed, 18 expected, SIR 1.5, 95\% CI 1.02.2). Eighteen of these cases had occurred after 1980 (11 expected, SIR 1.6, 95\% CI 1.0-2.6). There was no particular increase in prostatic cancer with increasing or decreasing time since first employment or in groups with first employment in different time periods.

All cases of lymphatic and hematopoietic and prostate cancer observed in the death register could also be found in the cancer register.

No cleaner with a lymphatic or hematopoietic tumor was found.

\section{Factory with particular excess of lymphatic and hematopoietic tumors}

Four of the workers who had died from lymphatic and hematopoietic tumors (expected 0.7, SMR 5.8, 95\% CI $1.6-15$ ), of whom there were 3 with multiple myeloma (expected 0.2, SMR 19, 95\% CI 3.9-55) and 1 with acute myelogenous leukemia, were employed at the same factory which contributed approximately $15 \%$ of the cohort population. In this factory the incidence for lymphatic and hematopoietic tumors was also increased (5 observed, 0.9 expected, SIR $5.4,95 \%$ CI 1.8 - 13), with 4 cases among those employed in 1956 or earlier $(0.7 \mathrm{ex}-$ pected, SIR 5.9, 95\% CI 1.6-15) and 1 case in the post1956 employment group. For all 5 cases more than 15 years had passed between first employment and diagnosis. The same 3 cases of multiple myeloma were identified in the cancer register as in the death register; 1 of the cases belonged to the post-1956 employment group.

\section{Discussion}

Our findings showed excess in deaths, as well as excess incidence, from lymphatic and hematopoietic tumors, particularly multiple myeloma, among workers employed in the paint industry before 1957. Some increase was also noted in the mortality and incidence of prostatic cancer, but no increase was noted in the mortality or morbidity from any other diagnosis. There was no excess mortality and morbidity from any diagnosis among the cleaners apart from genitourinary disease, for which the increase was due to the 3 deaths from urinary infections occurring before 1982 (1). The lack of such deaths in the entire cohort in the new follow-up period supports the probability that this excess was a chance finding.

Nine of the 10 lymphatic and hematopoietic tumors in the entire cohort appeared among the men employed in 1956 or earlier, and therefore there was an excess risk in this group. Consequently there were no indications of an excess risk for such tumors combined among the men first employed in 1957 and thereafter. Additional followup is warranted to determine if the same is true also for multiple myeloma. As was already mentioned, benzene was an important solvent in the industry before the mid1950s. Although some studies have suggested a possible link between benzene exposure and myeloma $(15,16)$, the association between benzene and acute myeloid leukemia is well established (17), and an obvious excess of such leukemia might have been expected if benzene exposure was the only cause of the excess myelomas. However, only 1 case of acute myeloid leukemia was found in the cohort. It is possible also that exposures to other solvents could have contributed. A case-referent study (18) showed that the relative risk of myeloma increased with the duration of exposure to benzene and other solvents. Elevated relative risks of multiple myeloma have been observed among painters in the United States (19), and in New Zealand as well (20). Furthermore, paint 
is a complex mixture of solvents, pigments, binders, and additives, and other exposures in the industry may also have contributed to the excess risk.

It is of interest that 5 of the 10 workers with the hematopoietic tumors were employed in the same factory, which contributed approximately $15 \%$ of the men to the cohort. Previous investigations of exposure conditions in the Swedish paint industry lead us to believe that no pronounced differences in work conditions, work practices, or exposures existed that would set apart this factory from the others which participated in the study. We have tried to obtain information on the worktasks of the workers with lymphatic and hematopoietic tumors in this factory, but the company was able to provide information only for the 2 workers who were still employed in the second half of the 1970s. One of these, who had a multiple myeloma diagnosed in 1988, had worked in the charging department of the factory. However, prior to his employment in the factory, he had worked in another paint factory that was bought by the factory included in our study in 1969. But it was unknown for how long he had worked in the other factory. The other worker, who had a multiple myeloma diagnosed in 1976, had, at least during the last years of his employment, worked in the department producing alkyds and other resins for paint production. We are thus unable to support or refute the common existence of particular work environment exposures among the workers in the factory with a particular excess of lymphatic and hematopoietic tumors, and the difference in the occurrence of these tumors between this factory and the others may be due to chance.

The literature on the relationship between work environment exposures and prostate cancer is limited, possibly due to the difficulty of studying prostate cancers when only death registers are available. It was, however, interesting that Brownson et al (21) identified paint manufacturing workers as having the highest risk for prostate cancer of all the occupations investigated (odds ratio $5.7,95 \%$ CI $1.4-24$ ) in their cancer register based case-referent study. Two other case-referent studies have found a significant association between exposure to mineral spirits and prostate cancer (22) and a nonsignificant association between solvent exposure and prostate cancer (23), respectively. The United States cohort of paint industry workers indicated no excess risk of mortality from prostate cancer $(3,4)$. In vitro studies have shown that prostatic epithelial cells often have an attenuated response to DNA-damaging agents (24). It is possible that this apparently inadequate response may predispose to xenobiotic-induced mutations in the prostate even at relatively low exposure levels.

The paint manufacturing plants studied were located in both larger cities and small communities all around southern Sweden, thus most regional differences were eliminated that might bias the comparisons with national mortality and cancer incidence rates (1). In order to estimate the effects of geographic differences in occurrence, we also calculated expected numbers for the factory with a particular excess of lymphatic and hematopoietic tumors based on the rates for men in the region where the factory was located. The SMR and SIR values based on regional rates were marginally lower than those based on national rates. The SMR for mortality from all lymphatic and hematopoietic tumors in this factory was 5.8 in the comparison with the national rates and 5.7 in the comparison with the regional rates. The corresponding SIR values were 5.4 and 4.9 , respectively. For myeloma the differences were even smaller.

Neither does it seem possible to explain the increased prostatic cancer incidence by regional differences. The rates for the regions where the paint factories were located were close to the national average. Moreover, out of the 27 incident cases of prostatic cancer in the cohort, only 1 was diagnosed only at autopsy. Therefore regional differences in autopsy frequencies can be excluded as a cause of the excess of prostatic cancer.

At the end of the follow-up, 1 January 1995, the cohort was elderly, with a mean age of 77 years (including those who were at that time already dead). If age and an occupational hazard work additively to increase the risk of a certain disease, the relative risk associated with the occupational hazard will diminish with time as the population under study ages. This trend may to some extent decrease the sensitivity of the closed cohort design applied in this study, particularly when common disorders are studied. However, when an occupational hazard shows a high relative risk for a rare disorder such as multiple myeloma, the association may be evident also in old age groups.

In conclusion, the findings of this follow-up show an increase in the incidence and mortality of lymphatic and hematopoietic tumors, particularly multiple myelomas, among workers first employed in the Swedish paint industry before 1957 . These excesses are likely to be causally linked to exposures previously occurring in the industry, or in parts of the industry. A significant excess of prostatic cancer was found which was not more or less pronounced among workers first employed in any particular period. This finding deserves further investigation since a similar finding has previously been made in the United States.

\section{Acknowledgments}

We wish to thank Annika Gustavsson and Karin Engström for their help with the data analysis. Thanks are also due to Johan Högberg and Bengt Sjögren for their comments on the manuscript. 
The follow-up was financed by the Swedish Council for Work Life Research.

\section{References}

1. Lundberg I. Mortality and cancer incidence among Swedish paint industry workers with long-term exposure to organic solvents. Scand J Work Environ Health 1986;12:108--13.

2. International Agency for Research on Cancer (IARC). Some organic solvents, resin monomers and related compounds, pigments and occupational exposures in paint manufacture and painting. Lyon: IARC, 1989. IARC monographs on the evaluation of carcinogenic risks to humans, vol 47.

3. Morgan RW, Hyg SM, Kaplan SD, Gaffey WR. A general mortality study of production workers in the paint and coatings manufacturing industry. J Occup Med 1981;23:13-21.

4. Morgan RW, Hyg SM, Claxton KW, Kaplan SD, Hyg SM, Parsons JM et al. Mortality of paint and coatings industry workers. J Occup Med 1985;27:377-8.

5. Bertazzi PA, Zocchetti C, Terzaghi GF, Guercilena S, Beretta F. Rischio cancerogeno nella produzione di Vernici: uno estudio di mortalita [carcinogenicity study of varnish production: a mortality study]. Med Lav 1981;6:465-72

6. International Agency for Research on Cancer (IARC). Dry cleaning, some solvents and other industrial chemicals. Lyon: IARC, 1995. IARC monographs on the evaluation of carcinogenic risks to humans, vol 63.

7. Olsson H, Brandt L. Supradiaphragmatic presentation of nonHodgkin's lymphoma in men occupationally exposed to organic solvents. Acta Med Scand 1981;210:415-8.

8. Olsson H, Brandt L, Risk of non-Hodgkin's lymphoma among men occupationally exposed to organic solvents. Scand J Work Environ Health 1988; 14:246-51.

9. Persson B, Dahlander A, Fredriksson M, Brage HN, Ohlson CG, Axelson O. Malignant lymphomas and occupational exposures. Br J Ind Med 1989;46:516-20.

10. Persson B, Fredriksson M, Olsen K, Boeryd B, Axelson O. Some occupational exposures as risk factors for malignant lymphomas. Cancer 1993;72:1773-8

11. Blair A, Linos A, Stewart P, Burmeister LF, Gibson R, Everett $\mathrm{G}$, et al. Comments on occupational and environmental factors in the origin of non-Hodgkin's lymphoma. Cancer Res 1992;52 suppl:5501-2.
12. Blair A, Linos A, Stewart P, Burmeister LF, Gibson R, Everett $\mathrm{G}$, et al. Evaluation of risks for non-Hodgkin's lymphoma by occupation and industry exposures from a case-control study. Am J Ind Med 1993;23:301—12.

13. Hardell L, Eriksson M, Degerman A. Exposure to phenoxyacetic acids, chlorophenols, or organic solvents in relation to histopathology, stage and anatomical localization of nonHodgkin's lymphoma. Cancer Res 1994;54:2386-9.

14. Marsh GM, Ehland J, Paik M, Caplan R. OCMAP/PC: a useroriented occupational cohort mortality analysis program for the IBM PC. Am Stat 1986;40:308-9.

15. Rinsky RA, Smith $A B$, Hornung R, Filloon TG, Young RJ, Okun AH, et al. Benzene and leukemia: an epidemiologic risk assessment. N Engl J Med 1987;316:1044-50.

16. Decoufle P, Blattner WA, Blair A. Mortality among chemical workers exposed to benzene and other agents. Environ Res 1983;30:16-25

17. International Agency for Research on Cancer (IARC). Overall evaluation of carcinogenicity: an updating of IARC monographs volumes 1 to 42. Lyon: IARC, 1987. IARC monographs on the evaluation of carcinogenic risks to humans, suppl 7.

18. La Vecchia C, Negri E, D'Avanzo B, Franceschi S. Occupation and lymphoid neoplasms. Br J Cancer 1989;60:385-8.

19. Demers PA, Vaughan TL, Koepsel TD, Lyon JL, Swanson GM, Greenberg RS, et al. A case-control study of multiple myeloma and occupation. Am J Ind Med 1993;23:629-39.

20. Bethwaite PB, Pearce N, Fraser J. Cancer risks in painters: a study based on the New Zealand Cancer Registry. Br J Ind Med 1990;47:742-6.

21. Brownson RC, Chang JC, Davis JR, Bagby JR. Occupational risk of prostate cancer: a cancer registry-based study. J Occup Med 1988;30:523-6.

22. Siemiatycki J, Dewar R, Nadon L, Gérin M, Richardson L, Wacholder S. Associations between several sites of cancer and twelve petroleum-derived liquids: results from a casereferent study in Montreal. Scand J Work Environ Health 1987;13:493-504.

23. Checkoway H, DiFerdinando G, Hulke BS, Mickey DD. Medical, life-style and occupational risk factors for prostate cancer. Prostate 1987;10:79-88.

24. Girinsky T, Koumenis C, Graeber TG, Peehl DM, Giaccia AJ. Attenuated response of $\mathrm{p} 53$ and $\mathrm{p} 21$ in primary cultures of human prostatic epithelial cells exposed to DNA-damaging agents. Cancer Res 1995;55:3726-31.

Received for publication: 7 May 1997 